\title{
Optimization of Draft Tube Position in a Spouted Bed Reactor using Response Surface Methodology
}

\author{
Elaheh Baghban, Arjomand Mehrabani-Zeinabad \\ Chemical Engineering Department, Isfahan University of Technology, Isfahan, Iran \\ Email: e.baghban@ce.iut.ac.ir
}

Received 2012

\begin{abstract}
Optimization of draft tube position in a spouted bed reactor used for treatment of wastewater containing low concentration of heavy metals is investigated in this paper. Response surface methodology is used to optimize the draft tube height, the draft tube width and the gap between the bottom of the draft tube and the inlet nozzle. It is observed that the draft tube with a height of 60 millimeter, width of 12 millimeter and the gap of 13 millimeter between its bottom and inlet nozzle, results in optimum value of minimum spouting velocity, measured 45 cubic centimeter per second (2.7 Liter per minute).
\end{abstract}

Keywords: Spouted Bed; Draft Tube; Minimum Spouting Velocity; Response Surface Methodology

\section{Introduction}

Low concentration of heavy metals in contaminated wastewater results in low reaction rates over electrode surface area and thus special considerations are necessary for reactor selection and design. Some of the most important requirements of these reactors are [1]:

- Large active surface area per unit reactor volume

- High mass transfer rate

- High current efficiency

- High current density

- Low cell voltage

- Uniform distribution of electrode potential

- Low maintenance cost

The spouted bed electrode studied at Berkeley in a collaborative effort with PASMINCO, the Australian zinc company, may significantly improve the electrodeposition of heavy metals. The spouted bed consists of a vessel filled with relatively coarse particles. A jet of fluid is injected vertically through a small opening located centrally at the base of the vessel. If the jet velocity is high enough, it causes a stream of particles to rise rapidly in a central core within the bed. As the jet expands above the bed, the fluid velocity drops and the particles fall out onto the top of an annular region surrounding the central jet. The particles then move slowly down in the bed until they are again swept up in the central jet. A spouted bed may incorporate a "draft tube"' to confine the spread of the central jet of fluid; in this way, spouted beds of large height-to-width ratio can also be operated. A spouting bed of conducting particles can then be made into an electrode by incorporating a current feeder and a diaphragm beyond which lies the counter electrode [2].

At low flow rates of electrolyte, there are no particles passing through the top of the draft tube and, therefore, no recirculation of particles. This is the "fixed bed zone"; the particles in the annular region are motionless. At higher flow rates, beyond a minimum spouting flow rate, particles issue from the top of the draft tube and recirculation occurs. This is the "stable spouted bed zone', The particles descend smoothly in the annular region. At a yet higher flow rate, the bed starts to behave irregularly, particularly in its upper regions, and the movement of particles in the annular region is no longer uniformly downward. It is conjectured that this "unstable spouted bed zone"' is incipient fluidization of the particles in the annular region [3].

Hydrodynamics of the spouted bed was investigated by Verma et al. [3], Piskova and Mörl [4], Duarte et al. [5], Shirvanian et al. [6,7] and Kazdobin et al. [8]. The positive effect of draft tube existence on the performance of the spouted bed reactor used for waste water treatment is obvious. In this paper the draft tube position and height of the spouted bed of figure 1 is optimized via response surface methodology.

\section{Methodology}

\subsection{Experimental Set-up and Procedure}

The dimensions of the spouted bed reactor of this study are shown in Figure 1. The draft tube (with rectangular cross section) was formed by vertical aluminum curved strips of different height in order to optimize the draft tube height (h), the draft tube width (d) and the gap dimension between the inlet nozzle and the bottom of the draft tube (g). The curvature of the bottom of the draft tube was designed due to gained results of the previous runs which confirm the positive effect of this curvature on decreasing the minimum spouting velocity. The inlet nozzle diameter was set to $4 \mathrm{~mm}$ based on previous runs in order to minimize the minimum spouting velocity as well as to create the stable spouting.

The reactor inlet flow enters from the inlet bottom nozzle after passing through a rotameter and exits from an opening inserted beside the reactor. The pressure drop was measured using a manometer. The Plexiglas construction and "flat"' geometry of the reactor provided the observation of the spouted bed, including the interior of the draft tube. 


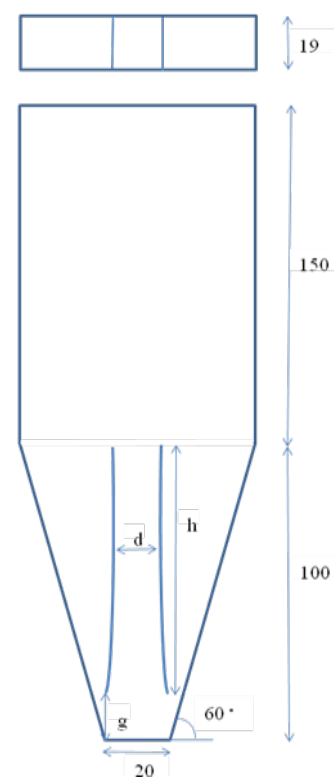

Figure 1. Spouted bed electrode of this experiment $(12<\mathrm{d}<24,60<\mathrm{h}$ $<100,13<\mathrm{g}<23$ ), All of the dimensions are in millimeter.

The reactor inlet flow increased gradually till the Copper particles (92.8\% mesh 16-20, 7.15\% mesh 20-30) were begun to sweep out of the apparatus from the "fountain" at the top of the draft tube. However this flow represents the minimum spouting velocity, but the result is not exactly reproducible as discussed by Epstein and Mathur [9]. A more reproducible result is obtained by increasing the flow more than the minimum spouting velocity and then slowly decreasing the flow: The bed then remains in the spouted state until the flow represents the reproducible minimum spouting velocity of the reverse process. A slight reduction of flow at this point causes the spout to collapse [9].

The reproducible minimum spouting velocity of the reverse process was obtained for different height, width and vertical gap between the inlet nozzle and the bottom of the draft tube in runs designed by response surface methodology in order to optimize the height and the position of the draft tube.

\subsection{Design of Experiment via Response Surface Me- thodology}

The response surface methodology (RSM) is a statistical and mathematical technique used for modeling and optimization of the processes in which a response of interest is influenced by several variables. It specifies the effect of the independent variables on the process, either individually or collectively. Furthermore, the experimental methodology generates a mathematical model describing the processes [10].

The design procedure of the response surface methodology is as follows $[10,11]$ :

- Determination of independent variables and their levels.

- Development of the best fitting mathematical model of the second order response surface.

- Determination of the optimal sets of experimental parameters that produce a maximum or minimum value of response.

- Obtaining the response surface plot and the contour plot of the response as a function of the independent parameters.

The total number of experiments required for this methodology is determined by [12]:

$$
\square \text { umber of experiments }=2^{k}+2 k+I
$$

where $k$ is the number of independent variables and $i$ is the number of random replications at the design center to evaluate the pure error.

The responses are related to variables by quadratic models, where $\eta \square$ is the response, $x_{i}$ and $x_{j}$ are coded variables, $\beta_{0}$ is the constant coefficient, $\beta_{\mathrm{j}}, \beta_{\mathrm{jj}}$ and $\beta_{\mathrm{ij}}$ are the interaction coefficients of linear, quadratic and the second-order terms, respectively and $e_{i}$ is the error [13]:

$$
\eta=\beta_{0}+\sum_{j=1}^{k} \beta_{j} x_{j}+\sum_{j=1}^{k} \beta_{j j} x_{j}^{2}+\sum_{i} \sum_{<j=2}^{k} \beta_{i j} x_{i} x_{j}+e
$$

In this experiment some of the effective hydrodynamic variables such as draft tube height, draft tube width and the gap between the draft tube bottom and the inlet nozzle were considered as independent variables and the minimum spouting velocity was the response. Each independent variable was coded at three levels between -1 and +1 where the variables of the draft tube width $\left(x_{1}\right)$, the draft tube height $\left(x_{2}\right)$ and the gap between the bottom of the draft tube and inlet nozzle $\left(x_{3}\right)$, were changed in the ranges $12-24 \mathrm{~mm}, 13-23 \mathrm{~mm}$ and $60-100 \mathrm{~mm}$. The critical ranges of selected parameters were determined by preliminary experiments based on literature experiences, our previous experiments and physical limitations.

Eighteen experiments were augmented with four replications at the design center as represented in Table 1. First four columns show run number and experimental conditions of the runs.

The result was related to the independent variables according to (2) using Design-Expert 7. 1. 3. program including ANOVA. The coefficients of determination R-Squared $\left(R^{2}\right)$ and Adj RSquared $\left(R_{a d j}^{2}\right)$ expressed the quality of fit of the resultant polynomial model, and statistical significance was checked by $F$-test in the program. For optimization, a module in DesignExpert software searched for a combination of factor levels that simultaneously satisfy the requirements placed on each of the responses and factors. The desired goal was selected as minimum spouting velocity.

\begin{tabular}{|c|c|c|c|c|c|}
\hline ஸू & Run & $\begin{array}{c}\text { Factor 1 } 1 \\
\text { A: Width } \\
\text { mm }\end{array}$ & $\begin{array}{c}\text { Factor } 2 \\
\text { B: Height } \\
\text { mm }\end{array}$ & $\begin{array}{c}\text { Factor } 3 \\
\text { C: Gap } \\
\text { mm }\end{array}$ & Response 1 \\
\hline & 1 & 0.0 & 0.0 & 0.0 & 60 \\
\hline & 2 & 0.0 & 0.0 & 1.0 & 70 \\
\hline & 3 & 1.0 & -1.0 & 1.0 & 58.3 \\
\hline & 4 & 0.0 & -1.0 & 0.0 & 55 \\
\hline & 5 & -1.0 & 0.0 & 0.0 & 51.7 \\
\hline & 6 & 1.0 & 1.0 & -1.0 & 70 \\
\hline & 7 & 0.0 & 0.0 & 0.0 & 60 \\
\hline & 8 & 1.0 & 1.0 & 1.0 & 80 \\
\hline & 9 & -1.0 & -1.0 & -1.0 & 45 \\
\hline & 10 & -1.0 & 1.0 & 1.0 & 75 \\
\hline & 11 & 1.0 & 0.0 & 0.0 & 60 \\
\hline & 12 & 0.0 & 0.0 & 0.0 & 60 \\
\hline & 13 & 0.0 & 0.0 & -1.0 & 56.7 \\
\hline & 14 & 1.0 & -1.0 & -1.0 & 56.7 \\
\hline & 15 & -1.0 & 1.0 & -1.0 & 51.7 \\
\hline & 16 & -1.0 & -1.0 & 1.0 & 55 \\
\hline & 17 & 0.0 & 1.0 & 0.0 & 70.0 \\
\hline & 18 & 0.0 & 0.0 & 0.0 & 58.3 \\
\hline
\end{tabular}

Table 1. Experimental results of the desined experiments. 


\section{Results}

\subsection{Optimization of Draft Tube Position via RSM}

The experimental results of the designed experiments shown in Table 1 were related to the independent variables as shown in (3):

$$
\begin{aligned}
\eta= & 59.78+4.66 A+7.67 B+5.82 C+1.04 A B-2.71 A C \\
& +2.71 B C-4.14 A^{2}+2.51 B^{2}+3.36 C^{2}
\end{aligned}
$$

ANOVA results of this quadratic model are presented in Table 2. In the table, model F-value of 148.51 implies that the model is significant. Prob $>\mathrm{F}$ is less than 0.05 for all terms, indicating that terms are significant for the equation. Adeq Precision of 48.508, which indicates an adequate signal to noise ratio, also confirms the model validity. The Pred R-Squared of 0.9298 is also in reasonable agreement with the Adj R-Squared of 0.9874 .

The results were optimized by Design-Expert software using the approximated function in (3). Optimized conditions under specified constraints were obtained for minimum height (6o $\mathrm{mm})$, minimum width $(12 \mathrm{~mm})$ and minimum vertical gap (13mm) of the designed draft tube. Under these optimized conditions, observed minimum spouting velocity was $45 \mathrm{~cm}^{3} / \mathrm{s}$. Equation (3) has been used to visualize the effects of experimental factors on responses in 3D graphs of Figure 2 and Figure 3.

Table 2. ANOVA results of the predicted quadretic model.

\begin{tabular}{lcccc}
\hline \multicolumn{1}{c}{ Source } & Sum of squres & Mean squre & F-Value & Prob $>$ F \\
\hline Model & 1347.30 & 149.70 & 148.51 & $<0.0001$ \\
Residual & 8.06 & 1.01 & & \\
Lack of Fit & 5.90 & 1.18 & 1.63 & 0.3644 \\
Pure Error & 2.17 & 0.72 & & \\
$\mathrm{R}^{2}=0.9941, \mathrm{R}^{2}{ }_{\text {adj }}=0.9874, \mathrm{R}^{2}{ }_{\text {Pre }}=0.9298$, Adeq Precision $=48.508$ \\
\hline
\end{tabular}

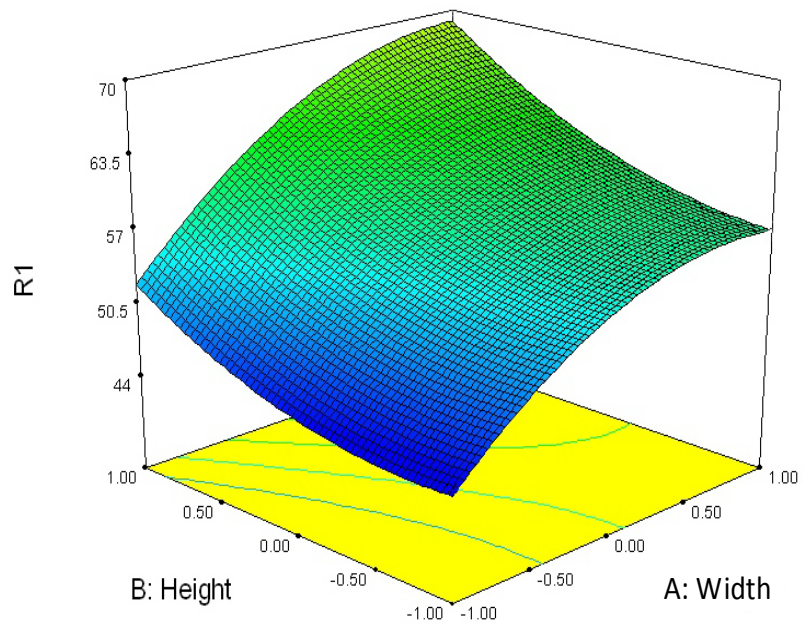

Figure 2. The effect of the draft tube height and width on minimum spouting velocity when the gap between inlet nozzle and draft tube is optimum.
The expected dependence of the draft tube height and minimum spouting velocity is shown in Figure 2. When the draft tube height is increased, the minimum energy required by the particles to sweep out of the draft tube is increased due to higher vertical distance. Consequently, the minimum required velocity for creating spout is increased. However decrease in the draft tube height has a positive effect on minimum spouting velocity and thus total energy requirements, buts it is limited by the filled bed height, which is six centimeter in this experiment.

Minimum spouting velocity is increased via increase of the draft tube width when the gap between the inlet nozzle and the draft tube is constant in its optimum value $\left(x_{3}=-1\right)$. The important role of the draft tube in the spouted bed reactor is to separate inner fluidized bed zone and outer packed bed zone. When the draft tube width is increased, the fluidization zone expands, but has no effect on the spouting zone created by the fluid jet. This means the bed operation approaches fluidized bed which requires more fluidization velocity to be fluidized. Despite the positive effect of decreasing the draft tube width on minimum spouting velocity, more decrease of the draft tube width, causes some of the agglomerated particles to stick in the tube and the bed stability to dissipate.

The gap between the inlet nozzle and the draft tube also has a noticeable effect on minimum spouting velocity as shown in Figure 3. Upon increasing the gap between inlet nozzle and draft tube, the fraction of the inflowing liquid diverted from the draft tube by passing up through the annular region is increased. Consequently, the internal jet power is deceased that must be compensated by higher spouting velocity.

\section{Conclusion}

In this paper, the dependence of minimum spouting velocity and the draft tube height, the draft tube width and the gap between the bottom of the draft tube and the inlet nozzle was investigated through experiments designed by response surface methodology. The mathematical model fitted by Design Expert software and validated by ANOVA, was used in order to optimize the mentioned variables.

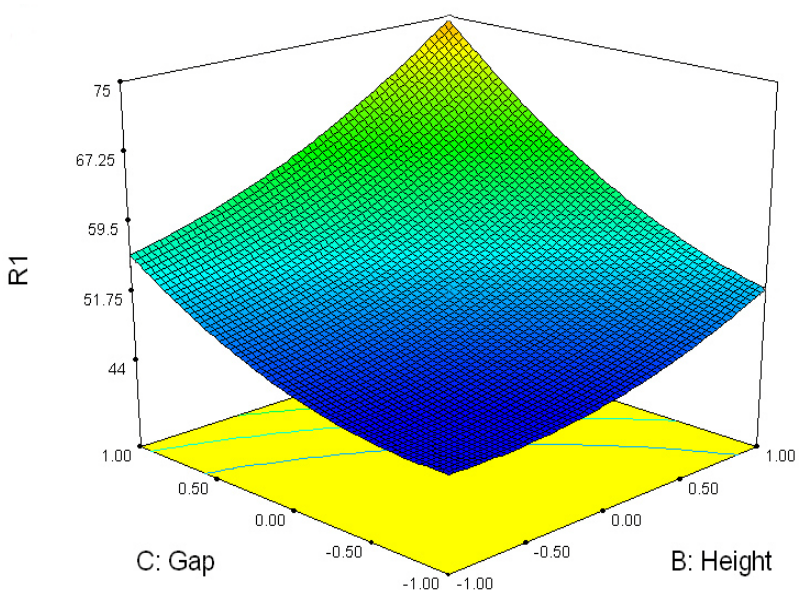

Figure 3. The effect of the draft tube height and the gap between inlet nozzle and the draft tube on minimum spouting velocity when the draft tube width is optimum. 
It was observed that the optimized draft tube height, draft tube width and the gap between the draft tube and the inlet nozzle are $60 \mathrm{~mm}, 12 \mathrm{~mm}$ and $13 \mathrm{~mm}$, respectively which represents the minimum spouting velocity of 45 cubic centimeter per second (2.7 Liter per minute).

\section{REFERENCES}

[1] K. Scott, “ Journal Review. Electrochemical Methods for the Treatment of Industrial Process Streams and Effluents. Part 1: Cell Design and the Recovery of Dissolved Metals by Electrodeposition”, Developments in Chemical Engineering and Mineral Processing, Vol. 1, pp. 185-197, October 1992.

[2] V. Jiricny, A. Roy, J. W. Evans, "Electrodeposition of Zink from Sodium Zincate/Hydroxide Electrolytes in a Spouted Bed Electrode”, Metallurgical and Materials Transactions, Vol. 31B, pp. 755-766, Aug, 2000

[3] A. Verma, J. C. Salas-Morales, J.W. Evans, "Spouted Bed Electrowinning of Zinc: Part II. Investigations of the Dynamics of Particles in Large Thin Spouted Beds", Metallurgical and Materials Transactions, Vol. 28B, pp. 69-79, Feb 1997

[4] E. Piskova and L. Mörl, "Fluidization regimes in different spouted bed apparatus constructions", Chemical Engineering and Processing, Vol. 46, pp.695-702, 2007.

[5] C. R. Duarte, V. V. Murata, A. S. Barrozo, “ Experimental and Numerical Study of Spouted Bed Fluid Dynamics”, Brazilian Journal of Chemical Engineering, Vol. 25, pp. 95-107,January-March 2008.
[6] P. A. Shirvanian, J. M. Calo, G. Hradil, “ Numerical Simulation of Fluid-Particle Hydrodynamics in a Rectangular Spouted Vessel”; Interrnational Journal of Multiphase Flow, Vol. 32, pp. 739-753, 2006.

[7] P.A. Shirvanian, J. M. Calo, "Hydrodynamic scaling of a rectangular spouted vessel with a draft duct”, Chemical Engineering Journal, Vol. 103, pp. 29-34, 2004

[8] K. Kazdobin, N. Shvab, S. Tsapakh, “ Scaling-up of Fluidized Bed Electrochemical Reactors”, Chemical Engineering Journal, Vol. 79 , pp. 203-209, October 2000

[9] K. B. Mathur., N. Epstein, “Spouted Beds”,Academic Press. Inc., 1974, pp. 15-25.

[10] R. Saravanathamizhan, N. Mohan, N. Balasubramanian, V. Ramamurthi , C. Ahmed Basha, " Evaluation of Electro-Oxidation of Textile Effluent Using Response Surface Method”, Clean, Vol.35, pp. 355-361, July 2007

[11] D. Granato, G. F. Branco, V. M. de Araüjo Calado, “ Experimental Design and Application of Response Surface Methodology for Process Modelling and Optimization: A Review”, Food Research International, 2001

[12] B. K. Körbahti, A. Tanyolaç. "Electrochemical Treatment of Simulated Textile Wastewater with Industrial Components and Levafix Blue CA Reactive Dye: Optimization through Response Surface Methodology”. Journal of Hazardous Materials, Vol. 151, pp. 422-431, 2008

[13] B. K. Körbahti, N. Aktaş, A. Tanyolaç.," Optimization of Electrochemical Treatment of Industrial Paint Wasteater with Response Surface Methodology', Journal of Hazardous Materials, Vol. 148, pp. 83-90, 2008. 